\title{
Deceased donor organ transplantation development in Mongolia
}

\author{
Altantulga Bayaraa, Battsetseg Gonchigjav, Midriimaa Purevjal, Batjargal Enkhee, Batchuluun Pandaan
}

Department of Cell Tissue and Organ Transplantation, National Center for Health Development, Ulaanbaatar, Mongolia

Background: Mongolia's Donor Law was first adopted in 2000 and amended in 2012 and 2018 respectively. The regulatory department for cells, tissues and organ transplantation of Center for Health Development has been established in 2018.

Methods: There are two transplant hospitals, one kidney transplant team, two liver transplant teams, three cornea transplant teams, one bone marrow transplant team, and four donor hospitals in Mongolia. To date, a total of 152 liver, 240 kidney, and 22 bone marrow transplantation had been performed successfully. Of these, 23 kidneys and 14 livers transplanted from 19 deceased donors. Our department gets information daily from donor hospital's brain death diagnosis committee, if there is a donor with brain death, we approach family members to get a consent approval.

Results: From 2018 to date, 158 possible donors have been detected. A total of 45 meetings (100\%) were held with possible donor families. Nineteen families (42.2\%) agreed and 26 families (57.7\%) refused. Of the 19 consent donors, 23 received a kidney and 14 liver transplants, saving 37 people's lives. As for the main reasons for 26 refusals, 14 families refused because of personal views, 10 families' religion and superstition, and inter-family issues-2.

Conclusions: We need to increase the number of donor hospitals and improve the knowledge of intensive care unit doctors and medical professionals. This will increase the detection of brain-dead donors and increase the number of organ transplants from brain-dead donors. In order to expand donor activities, we need to start organ transplantation from circulatory death donors. There is also a need to raise public awareness of donors and organize community-based activities.

Corresponding author: Altantulga Bayaraa

E-mail: altantulga@hdc.gov.mn

(C) The Korean Society for Transplantation

This is an Open Access article distributed under the terms of the Creative Commons Attribution Non-Commercial License (http://creativecommons.org/licenses/by-nc/4.0/) which permits unrestricted non-commercial use, distribution, and reproduction in any medium, provided the original work is properly cited. 